\title{
Synthesis of some 4-oxobenzotriazolo Hydrazones
}

\section{Harith Mohammad Al-Ajely}

\author{
Chemistry Department, college of Science, Mosul University, Mosul- Iraq \\ Harith_mahammed@yahoo.com
}

\begin{abstract}
New series of benzotriazolo hydrazones(15-19) were synthesized from the reaction of hydrazide of oxobenzotriazine (14) with some 4-aminobenzaldehydes (4-(pyrrolidin-1-yl)benzaldehyde (3), 4-(piperidin-1-yl) benzaldehyde (4), 4-morpholinobenzaldehyde(5) and 4-(1H-pyrazol-1-yl)benzaldehyde (6). Thesealdehydes were synthesized form the reaction of cyclic amines with 4-flourobenzaldehyde. The other type of aldehyde (7-methyl2-oxo-1,2-dihydroquinoline-3-carbaldehyde) (10) was synthesized in three steps starting from $m$-toluidine which was converted into amide (8), this amide was then transformed into (2-chloro-7-methylquinoline-3-carbaldehyde) (9) via Vilsmeier reaction and finally into (7-methyl-2-oxo-1,2-dihydroquinoline-3-carbaldehyde) (10). The synthesized compounds were studied using a combination of IR, NMR and Mass methods.
\end{abstract}

Keywords: oxobenzotriazol, hydrazone, 4-aminobenzaldehyde.

\section{INTRODUCTION}

Hydrazone is a class of organic compounds with the moiety $\mathrm{R}_{1} \mathrm{R}_{2} \mathrm{C}=\mathrm{NNH}_{2}$. This moiety plays an important key role in organic chemistry [1-7]. Generally, hydrazones can be synthesized by the reaction of the appropriate hydrazines/hydrazides with aldehydes or ketones in solvents such as ethanol, methanol, butanol tetrahydrofuran and glacial acetic acid [8-9] A wide range of hydrazones have been proved to posses interesting biological activities including anticonvulsant [10], anti-inflammatory [11], antimalarial [12], antioxidant [13], antituberculous [14], anti-HIV [15,16] and anti-prion activities [17]. Due to the stability of hydrazones at the neutral $\mathrm{pH}$ they are used to couple with certain drugs. Hydrazones were also found to have applications in drug design and many heterocyclic synthesis [18]. Due to the ease of preparation of hydrazones and their reactivity toward electrophiles and nuclophiles they are used for the synthesis of variety of organic compounds such as heterocyclic compounds. Therefore, they have been studied for a long time although, much of their chemistry still unexplored [19]. It was known that Pyrrolidine, Morpholine and 1H-pyrazole have a biological activities against many diseases [20-22]. Hydrazides them self were also found to have significant biological activities against certain diseases [23], therefore converting these hydrazides into the corresponding hydrazones may increase their biological activities according to the well know $\mathrm{C}=\mathrm{N}$ activity [18]. We reported here a new series of hydrazones containing these types of heterocyclic compounds. Furthermore, it was known that a large number of bioactive compounds and natural products containing the quinoline moiety in their skeletons have been investigated [24]. 3-substituted quinolone-2-one is one of the interesting moieties in compounds having anti-tumor activities was also investigated [25].

\section{EXPERIMENTAL}

All reagents were purchased from Sigma-Aldrich and used as supplied without further purification. Melting points were recorded on a Gallenkamp machine. ${ }^{1} \mathrm{H} /{ }^{13} \mathrm{C}$ NMR spectra were measured using a Bruker AV-1400 model NMR instrument at $400 \mathrm{MHz}$. Accurate mass measurements were achieved using a Water-Micromass LCT electrospray mass spectrometer. All reactions and measurements were accomplished at the chemistry department, university of Sheffield, United kingdom. Aldehydes (3-6) were synthesized following the elsewhere procedure [26]. Aldehyde (10) was synthesized following the published procedure [27]. Compound (11) was synthesized according to the well-known procedure [28]. Ester (13) was synthesized following the published procedure [29]. Hydrazide (4) was synthesized following an earlier published procedure [30]. The structure of all compounds were confirmed based on their analytical and spectral NMR, mass \& IR data and are well discussed. 
Synthesis of some 4-oxobenzotriazolo Hydrazones

\section{GENERAL PROCEDURE FOR THE SYNTHESIS OF HYDRAZONES (15-19)}

Equimolar quantities of hydrazide (14) and aldehydes 3, 4, 5, 6, or 10 were dissolved in $10 \mathrm{ml}$. absolute ethanol and refluxed for 3 hours. After the completion of the reaction (TLC monitoring), the mixture was allowed to cool to room temperature and concentrated by rotary evaporator. The residue was then purified by column chromatography using ethylacetate and petroleum ether 3:1 affording the pure product as a white solid. The physical and spectral data were presented bellow.

\section{RESULTS AND DISCUSSION}

New series of heterocyclic hydrazones were synthesized from the reaction of hydrazides of oxobenzotriazine with some 4-amino benzaldehyds. The reaction of 4-flourobenzaldehyde with some cyclic amines afforded aldehydes (3-6) (Scheme 1) which were allowed to react with hydrazide (14) forming hydrazones (15-18) in good percentage yield (Scheme 3). On the other hand, an aromatic aldehyde containing quinoline moiety was synthesized in three steps (as it was mentioned before) in which the m-toluidine was treated with phosphoric acid to form the corresponding amide (8) (Scheme 2). The amide was then converted into 2- chloro-7-methylquinoline3-carbaldehyde (9) via the Vilsmeier reaction using $\mathrm{POCl}_{3}$ in DMF. Subsequently, the formed aldehyde was treated with concentrated acetic acid to form 7- methyl-2-oxo-1,2-dihydroquinoline-3-carbaldehyde (10) which was allowed to react with hydrazide (14) forming the new hydrazone (19), (Scheme 3).

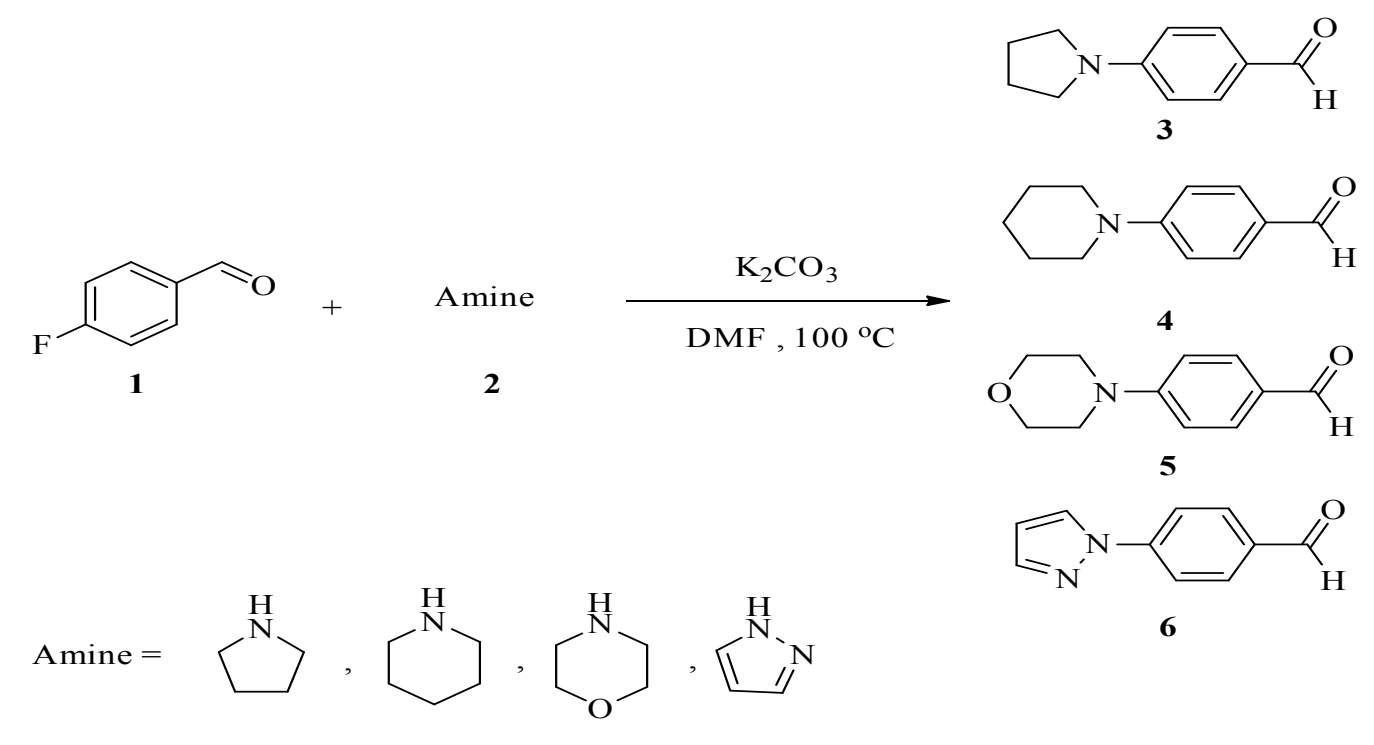

Scheme 1

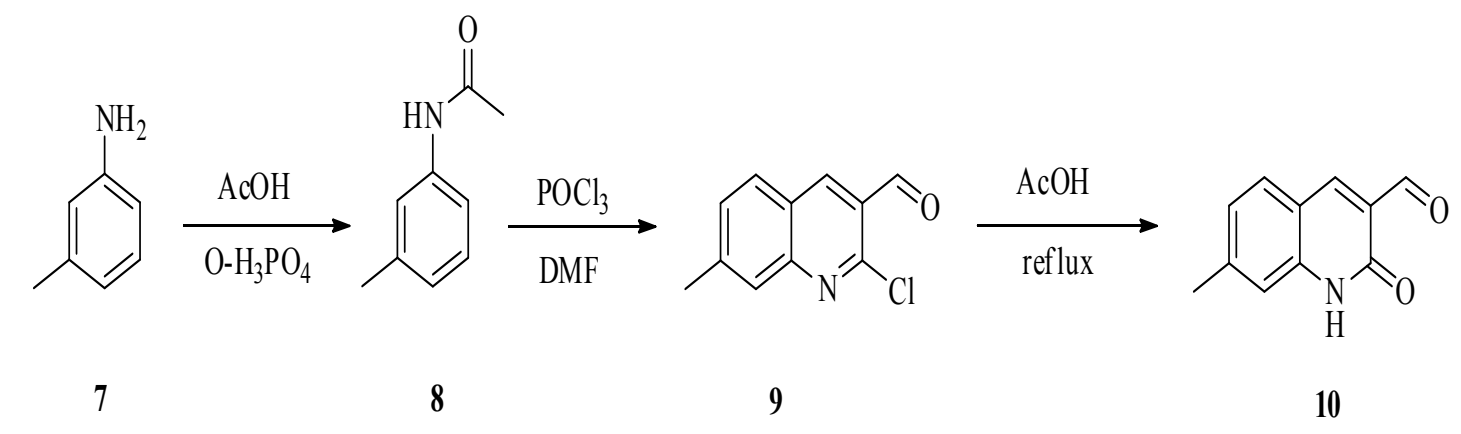

Scheme 2 
Synthesis of some 4-oxobenzotriazolo Hydrazones

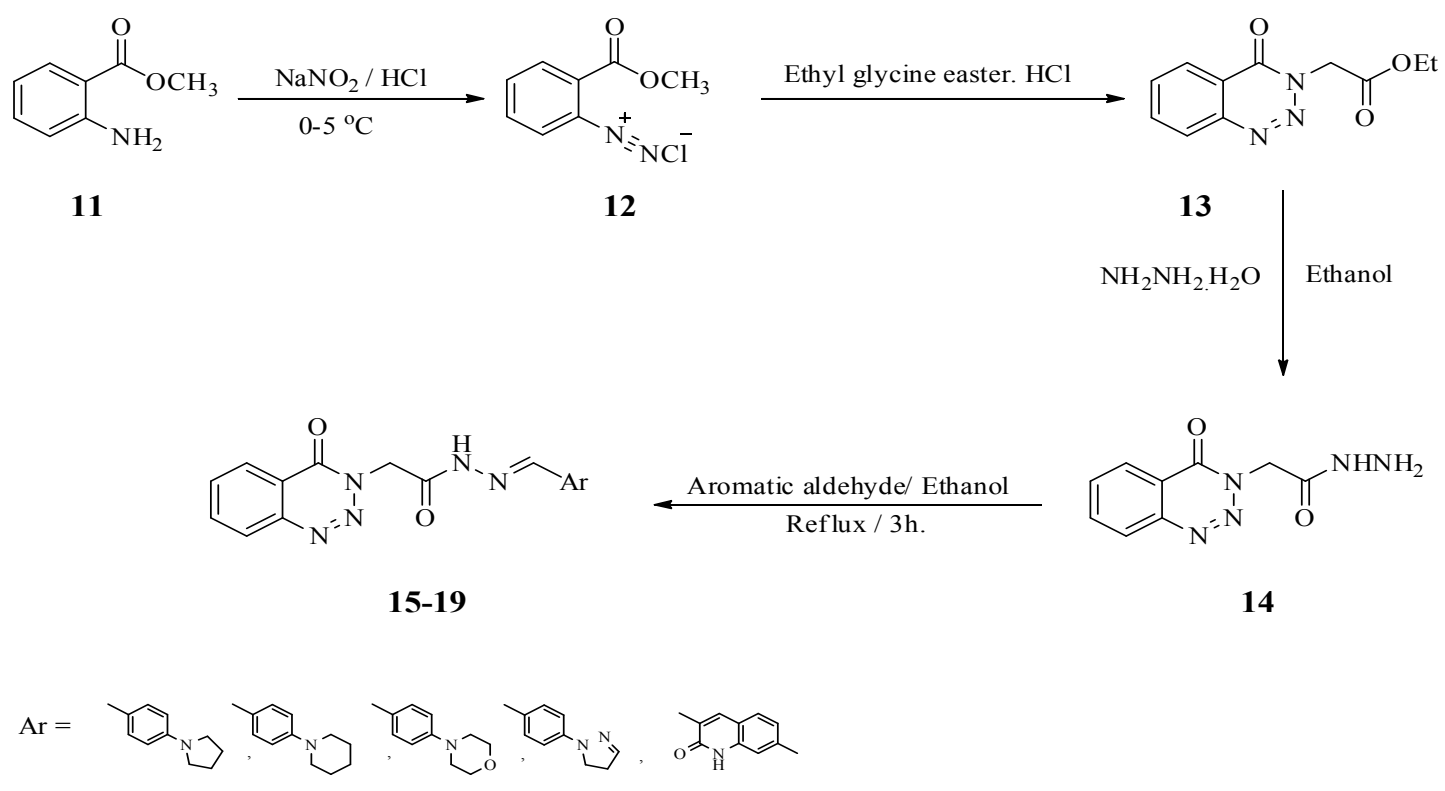

Scheme 3

The ${ }^{1} \mathrm{H}$ NMR data of the formed hydrazone (15) showed a singlet at $\delta 11.6$ for the $\mathrm{NH}$ group and two singlet at $\delta$ 5.6 and $\delta 5.2$ for $\left(\mathrm{CH}_{2} \mathrm{C}=0\right)$ resonating within the plane and out of the plane of the molecule respectively. While the ${ }^{13} \mathrm{C}$ NMR showed a signal at $\delta 167.3$ for the ( $\left.\mathrm{NHC}=0\right)$, a signal at $\delta 155.3$ for $(\mathrm{NC}=0)$ and a signal at $\delta 144.3$ for the $(\mathrm{C}=\mathrm{N})$ which confirmed the formation of the hydrazone. Furthermore, the IR spectra showed a broad peak at $3330 \mathrm{~cm}^{-1}$ for $(\mathrm{NH})$ group and two peaks at $1720,1663 \mathrm{~cm}^{-1}$ for $(\mathrm{C}=0)$ and $(\mathrm{C}=\mathrm{N})$ group respectively. The other synthesized compounds showed nearly the same absorption bands of IR functional groups and also the values of ${ }^{1} \mathrm{H}$ and ${ }^{13} \mathrm{C}$ NMR signals showed nearly the same for the selected sample above (15). It is worth noting that the ${ }^{1} \mathrm{H},{ }^{13} \mathrm{C}$ NMR and the IR values for the synthesized hydrazones were found in agreement with the values mentioned in similar published compounds [31,32]. The high resolution mass spectra for all the synthesized hydrazones were agreed with their calculated mass as shown bellow.

(E)-2-(4-oxobenzo[d][1,2,3]triazin-3(4H)-yl)-N'-(4-(pyrrolidin-1-yl)benzylidene) acetohydrazide (15).

White solid, mp: $146-147^{\circ} \mathrm{C} .67 \%$ yield. ${ }^{1} \mathrm{H}$ NMR (DMSO-d $\left.{ }_{6}, 400 \mathrm{MHz}\right): \delta 11.6$ (b, 1H, NH), 8.3-6.5 (m, $\left.8 \mathrm{Ar}-\mathrm{H}\right),(\mathrm{s}$, $1 \mathrm{H}, \mathrm{CH}), 5.5,5.1\left(\mathrm{~s}, 2 \mathrm{H}, \mathrm{CH}_{2}\right.$ in and out of the plane), $3.3\left(\mathrm{t}, 4 \mathrm{H}, \mathrm{J}=4.0\right.$ and $\left.3.0 \mathrm{~Hz}, \mathrm{CH}_{2}\right), 1.98\left(\mathrm{~m}, 4 \mathrm{H}_{1} \mathrm{CH}_{2}\right) .{ }^{13} \mathrm{C} \mathrm{NMR}$ (DMSO-d ${ }_{6}, 100$ MHz): $\delta 167.3,155.3,146.0,144.3,133.6,133.5,129.1,128.9,128.5,125.0,120.9,112.0,111.7$, 51.1, 47.7, 25.4. $v_{\max }$ (ATR) $\mathrm{cm}^{-1} 3330(\mathrm{NH}), 1720,1663(\mathrm{C}=0), 1603(\mathrm{C}=\mathrm{N}), 1337(\mathrm{C}-\mathrm{N})$. High resolution mass spectrum $\mathrm{m} / \mathrm{z} \%$ (ES): found 377.1742 requires for $\left(\mathrm{C}_{20} \mathrm{H}_{20} \mathrm{~N}_{6} \mathrm{O}_{2}[\mathrm{M}+\mathrm{H}]^{+}\right) 377.1726$.

(E)-2-(4-oxobenzo[d] $[1,2,3]$ triazin-3 $(4 \mathrm{H})$-yl)-N'-(4-(piperidin-1-yl)benzylidene) acetohydrazide (16).

White solid, mp: $152^{\circ} \mathrm{C} .63 \%$ yield. ${ }^{1} \mathrm{H}$ NMR (DMSO-d $\left.{ }_{6}, 400 \mathrm{MHz}\right): \delta 11.7$ (b, 1H, NH), 8.3-6.9 (m, 8 Ar-H), (s, $1 \mathrm{H}$, $\mathrm{CH}), 5.5,5.12\left(\mathrm{~s}, 2 \mathrm{H}, \mathrm{CH}_{2}\right.$ in and out of the plane), $3.4\left(\mathrm{~m}, 4 \mathrm{H}, \mathrm{CH}_{2}\right), 1.51\left(\mathrm{~m}, 6 \mathrm{H}, \mathrm{CH}_{2}\right) .{ }^{13} \mathrm{C} \mathrm{NMR}$ (DMSO-d ${ }_{6}, 100$ MHz): $\delta$ 167.5, 162.7, 152.8, 145.4, 144.3, 136.1, 133.6, 132.1, 125.0, 123.4, 119.6, 115.0, 113.5, 51.8, 51.1, 25.3, 24.3. $v_{\max }\left(\right.$ ATR $\mathrm{cm}^{-1} 3481(\mathrm{NH}), 1711,1653(\mathrm{C}=0), 1598(\mathrm{C}=\mathrm{N}), 1331(\mathrm{C}-\mathrm{N})$. High resolution mass spectrum $\mathrm{m} / \mathrm{z} \%$ (ES): found 391.1869 requires for $\left(\mathrm{C}_{21} \mathrm{H}_{22} \mathrm{~N}_{6} \mathrm{O}_{2}[\mathrm{M}+\mathrm{H}]^{+}\right) 391.1882$. 
Synthesis of some 4-oxobenzotriazolo Hydrazones

(E)-N'-(4-morpholinobenzylidene)-2-(4-oxobenzo[d] [1,2,3]triazin-3(4H)-yl)acetohydrazide (17).

White solid, mp: $141^{\circ} \mathrm{C} .66 \%$ yield. ${ }^{1} \mathrm{H}$ NMR (DMSO-d $\left.{ }_{6}, 400 \mathrm{MHz}\right): \delta 11.7$ (b, 1H, NH), 8.3-7.0 (m, $\left.8 \mathrm{Ar}-\mathrm{H}\right),(\mathrm{s}, 1 \mathrm{H}$, $\mathrm{CH}), 5.5,5.12\left(\mathrm{~s}, 2 \mathrm{H}, \mathrm{CH}_{2}\right.$ in and out of the plane), $3.75\left(\mathrm{t}, 4 \mathrm{H}, \mathrm{J}=4.0 \mathrm{~Hz}, \mathrm{CH}_{2}\right), 3.2\left(\mathrm{t}, 4 \mathrm{H}, \mathrm{J}=4.0 \mathrm{and} 3.0 \mathrm{~Hz}, \mathrm{CH}_{2}\right.$ ). ${ }^{13} \mathrm{C}_{\text {NMR }}$ (DMSO-d ${ }_{6}, 100 \mathrm{MHz}$ ): $\delta$ 167.6, 155.3, 152.6, 145.3, 144.3, 136.1, 133.6, 128.8, 128.6, 125.0, 124.6, 119.6, 114.8, 66.4, 51.1, 47.9, 24.3. $v_{\max }\left(\right.$ ATR) $\mathrm{cm}^{-1} 3194(\mathrm{NH}), 1702,1665(\mathrm{C}=\mathrm{O}), 1564(\mathrm{C}=\mathrm{N}), 1331(\mathrm{C}-\mathrm{N})$. High resolution mass spectrum $\mathrm{m} / \mathrm{z} \%$ (ES): found 393.1691 requires for $\left(\mathrm{C}_{20} \mathrm{H}_{20} \mathrm{~N}_{6} \mathrm{O}_{3}[\mathrm{M}+\mathrm{H}]^{+}\right) 393.1675$.

(E)-N'-(4-(1H-pyrazol-1-yl) benzylidene)-2-(4-oxobenzo[d] [1,2,3]triazin-3 (4H)-yl) acetohydrazide (18).

White solid, mp: $147-148{ }^{\circ} \mathrm{C} .64 \%$ yield. ${ }^{1} \mathrm{H}$ NMR (DMSO-d $6^{\prime}$ 400MHz): $\delta 11.9$ (b, 1H, NH), 8.6-6.6 (m, $11 \mathrm{Ar}-\mathrm{H}$ ), $(\mathrm{s}, 1 \mathrm{H}, \mathrm{CH}), 5.62,5.2\left(\mathrm{~s}, 2 \mathrm{H}, \mathrm{CH}_{2}\right.$ in and out of the plane). ${ }^{13} \mathrm{C}$ NMR (DMSO-d $\left.\mathrm{f}, 100 \mathrm{MHz}\right): \delta 168.1,163.3,155.3$, 147.0, 144.3, 144.1, 141.9, 141.0, 136.2, 133.6, 132.0, 128.8, 128.7, 128.6, 128.4, 125.0, 51.1. $v_{\max }$ (ATR) cm ${ }^{-1}$ $3124(\mathrm{NH}), 1699,1670(\mathrm{C}=0), 1528(\mathrm{C}=\mathrm{N}), 1336(\mathrm{C}-\mathrm{N})$. High resolution mass spectrum $\mathrm{m} / \mathrm{z} \%$ (ES): found 374.1370 requires for $\left(\mathrm{C}_{19} \mathrm{H}_{15} \mathrm{~N}_{7} \mathrm{O}_{2}[\mathrm{M}+\mathrm{H}]^{+}\right) 374.1365$.

(E)-N'-((7-methyl-2-oxo-1,2-dihydroquinolin-3-yl)methylene)-2-(4-oxobenzo[d][1,2,3] triazin-3(4H)-yl)acetohydrazide (19).

White solid, mp: $168{ }^{\circ} \mathrm{C} .64 \%$ yield. ${ }^{1} \mathrm{H}$ NMR (DMSO- $\left.{ }_{6}, 400 \mathrm{MHz}\right): \delta 12.0$ (b, $2 \mathrm{H}, \mathrm{NH}$, overlapped on each other), 8.5-7.0 (m, $8 \mathrm{Ar}-\mathrm{H}),(\mathrm{s}, 1 \mathrm{H}, \mathrm{CH}), 5.62,5.2\left(\mathrm{~s}, 2 \mathrm{H}, \mathrm{CH}_{2}\right.$ in and out of the plane), $2.4\left(\mathrm{~s}, 3 \mathrm{H}, \mathrm{CH}_{3}\right) .{ }^{13} \mathrm{C}$ NMR (DMSO-d $\mathrm{d}^{\prime}, 100$ MHz): $\delta 168.1,161.5,155.4,144.3,142.1,140.2,139.7,136.2,135.3,133.6,129.2,128.6,125.0,124.4,119.5,117.4$, 115.3, 51.2, 22.0. $v_{\max }$ (ATR) cm-1 3387 (NH, quinolin), $3083(\mathrm{NH})$ 1673, $1645(\mathrm{C}=\mathrm{O}), 1566$ (C=N), $1334(\mathrm{C}-\mathrm{N})$. High resolution mass spectrum $\mathrm{m} / \mathrm{z} \%$ (ES): found 389.1376 requires for $\left(\mathrm{C}_{26} \mathrm{H}_{20} \mathrm{~N}_{6} \mathrm{O}_{3}[\mathrm{M}+\mathrm{H}]^{+}\right) 389.1362$.

\section{CONCLUSION}

From the above study, we conclude that the new hydrazide was successfully synthesised by hydrazenolysis of the cprresponding ester. The structure of the final hydrazone compounds were also confirmed by the spectral methods stated above. These compounds might be important in medical applications especially as anti-prion diseases agents which will be investigated in our next work.

\section{ACKNOWLEDGMENTS}

The authors would like to thank the chemistry department of Sheffield university in the United Kingdom for their cooperation and providing the facilities to do this work.

\section{REFERENCES}

1. Turan-Zitouni G, Blache Y and Güven K. .Boll. Chim.Farm. 140 (2001) 397-400.

2. Peng G. and Yunyang W. Heterocyclic Communications., 19 (2013) 113 - 119.

3. Samudranil P. and Balavardhana R. Journal of Organometallic Chemistry. 731 (2013) 67 - 72.

4. Chang, Junbiao; Huang, Gang; Liu, Hongxu; Yu, Wenquan; Zhang, Yueteng; Chang, Junbiao; Dong, Lihong; Li, Yujiang; Yu, Xuejun Journal of Organic Chemistry. 78 (2013) 10337 - 103431.

5. Lamaty, Frederic; Martin, Charlotte; Martinez, Jean; Nun and Pierrick. Tetrahedron. 67 (2013) 8187 -8194.

6. Chen, Ke; Hu, Yang; Li, Qing-Shan; Lu, Xiang; Yan, Ru; Zhu, Hai-Liang Bioorg. Med. Chem. 20 (2012) 903 - 909.

7. Jacobsen N. Eric T. and Kian L. Angewandte Chemie - International Edition.,46 (2007), 1315 - 13171.

American Research Journal of Chemistry

Page 14 
Synthesis of some 4-oxobenzotriazolo Hydrazones

8. Stork G.and Benaim J. Org. Synth. 6 (1977) 242.

9. Day A. C.and Whiting M. C. Org. Synth. 6 (1970) 10.

10. Sridhar SK. "Anticonvulsant activity of hydrazones, Schiff and Mannich bases of isatin derivatives". European Journal of Pharmaceutical Sciences 16.3 (2002) 129-132.

11. Ramin H. "Microwave Assisted Efficient One-pot Synthesis,Characterization of Organophosphorus Based Hydrazone Derivatives under Solvent-Free Conditions and Their Antimicrobial Activity Middle-East". Journal of Scientific Research 13.9 (2013) 1186-1189.

12. Zafer D. and Asım K. "Synthesis and Biological Evaluation of Some Hydrazone Derivatives as Anti-inflammatory Agents". Letters in Drug Design \& Discovery 9 (2012) 310-315.

13. AG Yadav, V.N. Patil , A.L. Asrondkar , A.A. Naik and P.V. Ansulkar. "anti-oxidant and anti-microbial activities of pyrazolyl-benzothiazole derivatives using vilsmeier-haack reaction". Rasayan journal of chemistry 5.1 (2012) 117-120.

14. Andreani A., Burnelli S., Granaiola M., Leoni A., Locatelli A., Morigi R., Rambaldi M., Varoli, L., Calonghi N., Cappadone C., Farruggia G., Zini M., Stefanelli C., Masotti L., Radin N. and Shoemaker R. J. Med. Chem. 51( 2008) 809.

15. Noulsri E., Richardson R., Lerdwana S., Fucharoen S., Yamagishi T., Kalinowski D. and Pattanapanyasat K. Am. J.Hematology. 84 (2009) 170.

16. Chen K., Tan Z., He M., Li J., Tang S., Hewlett I., Yu F., Jin Y.and Yang M. Structure-Activity relationships(SAR) research of thiourea derivatives as dualinhibitors targeting both HIV-1 capsid and humancyclophilin A. Chem Biol Drug Des. 76(1) (2010) 25-33.

17. Duo Lu, Kurt Giles, Zhe Li, Satish R. and Elena D., J. Pharmacol. Exp. Ther. 347, November (2013) 325-338.

18. Anna M. Wu \& Peter D. Senter, "Arming antibodies: prospects and challenges for immunoconjugates," Nature Biotechnology. 23 ( 2005) 1137-1146.

19. Nataliya P. Belskaya, Wim Dehaen, and Vasiliy A. Bakulev. "Synthesis and properties of hydrazones bearing amide, thioamide and amidine functions". ARKIVOC (2010) 275-332.

20. Beining. C, and Pratt S. Library design, synthesis, and screening: pyridine dicarbonitriles as potential prion disease therapeutics. J. Med. Chem. 26;49(2) (2006) 607-15.

21. Kalpesh S. Parikh and Sandip P. Vyas. Design, Characterization and Biological Activity of a new series of sTriazines Derived with Morpholine. Journal of Applied Pharmaceutical Science 2 (05) (2012) 111-114.

22. Jahangir A. , Ozair A. , Perwaiz A. and Mohd J. Naim. A Review on Pyrazole chemical entity and Biological Activity. International Journal of Pharma Sciences and Research. 6 (2015) 1433-1442.

23. Strappaghetti G., Brodi C. and Giannaccini G. Bioorg.Med.Chem.Lett. 16 (2006) 2575-2579.

24. Egan T. J. Inorg. Biochem.100 (2006) 916.

25. Connell, R. D. Expert Opin. Ther. Pat. 12, (2002) 1763.

26. Deepak K., Kranthi R., MaiAnn B., Torey A., Tanya P. and Diwan S. Bioorg. Med. Chem. Lett. 23 (2013) 1365.

27. Mrityunjay K. Singh, Atish C. Bahawana S. and Radhey M. Tetrahedron Lett. 48 (2007) 5987.

American Research Journal of Chemistry

Page 15 
Synthesis of some 4-oxobenzotriazolo Hydrazones

28. Wiklund P. and Bergman J. "The Chemistry of Anthranilic Acid," Current Organic Synthesis. 3 (2006) 379-402.

29. Krishnan H., Muni M., and N.Sahruna S. J. Adv. Chem. 4 (2014) 266-275 .

30. Mohammad S. Al-Ajely and Aymen N. Yaseen International Journal of Scientific \& Engineering Research. 7 (2016) 1372-1376

31. Harsha I. N., Reshma N. I., Manoj K. and Prabhjeet K. Synthesis and in-vitro screening of novel dihydropyrimidine derivatives as potential calcium channel blockers, DerPharma chemical. 6 (2014) 221-227,.

32. Mohammad S. Al-Ajely and Aymen N. Yaseen . Chemistry Journal. 6 (2016) 18-23.

Citation: Harith Mohammad Al-Ajely, "Synthesis of some 4-oxobenzotriazolo Hydrazones". American Research Journal of Chemistry, 1(1); pp: 11-16.

Copyright (C) 2017 Harith Mohammad Al-Ajely, This is an open access article distributed under the Creative Commons Attribution License, which permits unrestricted use, distribution, and reproduction in any medium, provided the original work is properly cited. 